civilisations, will have been irreparably damaged or entirely destroyed. In order that something at least may be saved, the Soviet Academy for the History of Early Culture has again asked for the co-operation of the University of Pennsylvania Museum. As the level of the water has already been raised $19 \mathrm{ft}$. in the past year, it will be possible to save only a limited amount by excavation before next autumn, when the work is to be completed. Yet the value of the material which is thus being lost to archæological science is incalculable. Not merely has the north Caucasus been examined only very imperfectly, but also the implications of the discoveries already made in this area are very little appreciated. On this point it is worth while to glance at a communication by Prof. V. L. Avdief of Moscow on the relations of the Caucasus and early Egypt, which appears in Ancient Egypt and the East, Pts. 1-2; 1933. Prof. Avdief points out that the most valuable evidence on the cultural relations of the Caucasus and the countries of the ancient East is to be expected from the monuments of the chalcolithic and bronze age cultures of the Koban type in the Euxine region. In the Ossetian and Kabarda-Balkaria Autonomous Region of the North Caucasus, where the author conducted excavations in 1931-32, the bronze and chalcolithic cultures are well developed. Here there were extensive deposits of copper ore, which indeed are not yet exhausted. In prehistoric times the tribes constantly extracted and worked these ores. The numerous bronze objects recently discovered in that area present close resemblances to those found at Koban. For example, a small stone hatchet, possibly ceremonial, found near Nalchik, fairly polished, with a central bored hole and partly bent downward, resembles one found at Koban. The pottery with incised line decoration painted white, the representa. tion of animals in bronze akin to the Koban 'animal style' and finally the mode of burial in stone cists exemplify the same relation.

Certain objects found at Balkaria show relation. ship with ancient Egyptian culture. One of the most striking is an anthropomorphic deity standing in the middle of a circle which may symbolise the sun. It is comparable to a representation of the god Bes or Pateka. Late Egyptian (Hellenistic or Roman) objects found in Balkaria prove cultural or commercial relations in the first millennium B.C., and these relations are shown by a number of objects of domestic purpose to have extended to Assyria and Babylonia, although the actual trade routes are difficult to establish.

\title{
Energy Relationships in Chemical Reactions
}

$\mathrm{I}^{\mathrm{N}}$ opening a discussion at the Royal Society on May 10 on the "Energy Distribution in Molecules in Relation to Chemical Reactions", Mr. C. N. Hinshelwood referred to some unimolecular reactions in which the velocity curve seems to be composed of several curves superposed, and suggested an interpretation in which several virtually independent reactions are taking place at the same time, all unimolecular and differing only in the values of the various characteristic constants. It is supposed that once a molecule has received its activation energy, the internal rearrangement of this is relatively difficult, and according to the original way in which the energy was placed in the molecule, there will be a different probability of chemical decomposition.

Investigations show that, with certain substances, molecules with activation energy differently located or distributed seem to behave as virtually independent entities for kinetic purposes, that there is a limited number of types of such molecules, and that the chance that activation energy is communicated to a molecule in such a way as to cause rapid decomposition is relatively much greater in substituted molecules such as $\mathrm{C}_{2} \mathrm{H}_{5} \mathrm{CHO}$ as compared with $\mathrm{HCHO}$. Investigations in liquid systems seem to suggest that there are two extreme cases, in one of which the rate of reaction is primarily determined by the acquisition of the necessary activation energy, and in the second a probability factor independent of temperature is of equal or greater importance and the reaction velocity is many powers of ten smaller than the activation rate.

There is a suggestive connexion between this and the remarkable catalytic effect of solvents, often roughly parallel with their polarity, on one hand, and on the other hand with the fact that, in reactions where one of the reactants is an ion, the rate is usually nearly equal to the activation rate, as though the great electrostatic forces contributed a perturbation powerful enough to increase the transformation probability to nearly unity.

\section{Barking Power Station}

\section{$\mathrm{T}$} HE new generating station of the County of London Electric Supply Co., Ltd., is situated at Barking on the bank of the River Thames, about half a mile below Barking Creek. Its output is now 390,000 kilowatts, the largest in Britain, and when completed it will be about 600,000 kilowatts and will probably be the largest in Europe. It plays the leading part for the south-east England area in the Central Electricity Board's scheme. Ten circuits converge on Barking, six at 132 kilovolts and four at $66 \mathrm{kv}$. The Board's transforming station is situated on the opposite side of the road to the power station and is equipped with several very large high-tension transformers.
The Company with its associated companies supply power over an area of about 3,000 square miles. It supplies four London boroughs and a large number of the inner suburbs. In addition, it supplies various districts in Surrey and Essex. The associated com. panies feed large parts of Kent and Sussex. It is also developing outer areas under various electrification schemes. According to Distribution of Electricity of February, published by Messrs. W. T. Henley's Telegraph Works, it is intended ultimately to provide a supply for each village or township in the area having a population of 500 or more persons. In addition, transmission lines along the route will in due course be tapped at any point where a demand 
exists. There are now more than seventy towns and villages where electric supply is available. There are several large poultry farms where electric hatcheries are in operation. Farms also use the electric supply for fruit and vegetable canning, and there are flour mills, small water and sewerage schemes, gravel and sand pits, brick-making and timber yards and sawing mills where it is employed. In addition to supplying electricity in bulk to many supply undertakings, it also supplies for traction purposes the London, Midland and Scottish Railway and the London Passenger Transport Board (Morden Tube).

The new extensions of the Barking power station work with a boiler pressure of $600 \mathrm{lb}$. per sq. inch. The temperature of the steam is therefore about $800^{\circ} \mathrm{F}$. A few years ago it looked as if a still higher pressure would become the standard. In America, steam pressures of $1,200 \mathrm{lb}$. per sq. inch were first used; later, pressures above 3,000 lb. per sq. inch were used in Europe. Seeing that the new Battersea power station works at between $600 \mathrm{lb}$. and $650 \mathrm{lb}$. pressure and that the new Fulham station is being designed for this pressure, it looks as if $650 \mathrm{lb}$. would become the standard pressure. It is interesting to remember that early steam boilers worked with pressures of about $8 \mathrm{Ib}$.

\section{University and Educational Intelligence}

CAmbridge.-The following appointments have been made :-J. H. Driberg, University lecturer in anthropology, Dr. S. Dickinson, University lecturer in mycology in the Department of Agriculture, W. J. Dowson (Christ's College), University lecturer in mycology in the Department of Botany and Dr. H. Godwin (Clare College), University lecturer in botany.

The degree of M.A. honoris causa has been conferred on Sir Charles Martin, formerly director of the Lister Institute of Preventive Medicine and professor of experimental pathology in the University of London.

At Girton College Dr. O. Taussky and Dr. C. Leubuscher have been elected to research fellowships.

On June 6, the following honorary degrees, among others, were conferred : Sc.D., Prof. Alfred Fowler, Yarrow research professor of the Royal Society and professor of astrophysics in the Imperial College of Science : Litt.D., Prof. Samuel Alexander, honorary professor of philosophy in the University of Manchester.

LIVERPoot.-The Council of the University has accepted with regret the resignation of Mr. R. O. Street, senior lecturer in applied mathematics, on his appointment to the chair of mathematics in the Royal Technical College, Glasgow.

The University of Berne has conferred the honorary degree of D.Sc. on Prof. Share Jones, director of veterinary studies and professor of veterinary anatomy in the University, in recognition of his services to veterinary education and his distinction in his own branch of research.

SHEFFIELD.-Whe title of emeritus professor has been conferred on Prof. Edward Mellanby, formerly professor of pharmacology in the University.

\section{Science News a Century Ago}

The Royal Society

At the meeting held on June 19, 1834, fourteen papers were taken; amongst these, a paper submitted on borings and ravages in timber, by William Thomp. son, vice-president of the Natural History Society of Belfast, was widely reported at the time. The opinion advanced that the Teredo navalis had ceased to be found on the British coast was-shown by the author to be erroneous, since numerous specimens had been collected from the piles used in the formation of the pier at Portpatrick, in Ayrshire.

The subjoined letter from Mr. J. G. Children, Sec. R.S., addressed to Mr. Francis Baily, vicepresident, was read: "British Museum, June 19, 1934. . . . His Royal Highness the President requests that, when you adjourn the meeting this evening to the 20th of November, you will have the goodness to express his great regret, that unfortunately, the state of his health and sight has lately been such as to render it impossible for him to preside at the ordinary meetings of the Society so regularly as it was his anxious wish to have done. His Royal Highness begs you will assure the Society that his absence has been occasioned by the cause alluded to alone, and from no feeling of diminished interest in the prosperity of the Royal Society, or of regard and respect for the Fellows; on the contrary His Royal Highness hopes that by the blessing of Providence, his health will soon be in all respects so far re-established as to enable him, on the reassembling of the Society, to resume the chair and fill it with that uninterrupted regularity which it is His Royal Highness's most anxious wish to observe, in whatever duty he undertakes. PS. His Royal Highness requests you will in his name bid the Fellows heartily farewell till he meets them again in November. (Proc. Roy. Soc., vol. 3.)

\section{Cause of the Aurora Borealis}

A paper "On the Nature and Origin of the Aurora Borealis" by the Rev. George Fisher, read before the Royal Society on June 19, forms an excellent illus. tration of the state of geophysics in 1834. Arguing from "the general fact that the Aurora Borealis is developed chiefly on the edge of the Frozen Sea, or wherever there is a vast accumulation of ice", the author concludes that it "is an electrical phenomenon, arising from the positive electricity of the atmosphere, developed by the rapid condensation of the atmosphere in the act of freezing, and the induced negative electricity of the surrounding portions of the atmosphere ; and that it is the immediate consequence of the restoration of the equilibrium by the intervention of the frozen particles, which being imperfect conductors, become luminous while transmitting this electricity. In tropical and temperate climates this phenomenon does not occur, because the electric equilibrium is restored by means of aqueous vapours, a process which often gives rise to thunder and lightning. . . ."

\section{Lardner on Babbage's Calculating Machine}

A century ago, few men of science were more widely known than Dr. Dionysius Lardner (1793-1859), who from 1827 until 1840 held the chair of natural philosophy and astronomy in University College, London. The writer of many textbooks, he projected the "Cabinet Cyclopaedia" and secured for it the 